\title{
Evidence for atmosphere - ocean meridional energy transport compensation in the past decades
}

Wilco Hazeleger (Utrecht University)

Yang Liu (NLeSC, WUR)

Jisk Attema ( NLeSC) 


\section{Background}

This research is supported by Blue Action project (European Union's Horizon 2020 research and innovation program, Grant 727852).

More details about this work can be found in the paper:

Liu, Y.,Attema, J., \&Hazeleger, W. (2020). Atmosphere-Ocean Interactions and Their Footprint on Heat Transport Variability in the Northern Hemisphere. Journal of Climate, 33(9), 3691-3710.

${ }^{\partial}$ Atmosphere-Ocean Interactions and Their Footprint on Heat Transport Variability in the Northern Hemisphere ${ }^{0}$

YANG LIU

Netherlands eScience Center, Amsterdam, and Wageningen University, Wageningen, Netherlands

JISK ATTEMA

Netherlands eScience Center, Amsterdam, Netherlands

WILCO HAZELEGER

Wageningen University, Wageningen, and Faculty of Geoscience, Utrecht University, Utrecht, Netherlands

(Manuscript received 26 July 2019, in final form 8 January 2020)

ABSTRACT Interactions between the atmosphere and ocean play a crucial role in redistributing energy, thereby
maintaining the energy balance of the climate system. Here, we examine the compensation between the atmosphere and ocean's heat transport variations. Motivated by previous studies with mostly numerical climate models, this so-called Bjerknes compensation is studied using reanalysis datasets. We find that at mospheric energy transport (AMET) and oceanic energy transport (OMEI) variability generally agree well among the reanalysis datasets. With milpie reanalysis products, we show that Bjerknes compensation is scales. The compensation rates peak at different latitudes across different time scales, but they are always located in the subtropical and subpolar regions. Unlike some experiments with numerical climate models, which attribute the compensation to the variation of transient eddy transports in response to the changes of OMET at multidecadal time scales, we find that the response of mean flow to the OMET variability leads to the Bjerknes compensation, and thus the shift of the Ferrel cell at midlatitudes at decadal time scales in primarily wind driven. In summer, there is hardly any compensation and the proposed mechanism is not applicable. Given the short historical records, we cannot determine whether the ocean drives the atmospheric variations or the reverse.

netherlands 


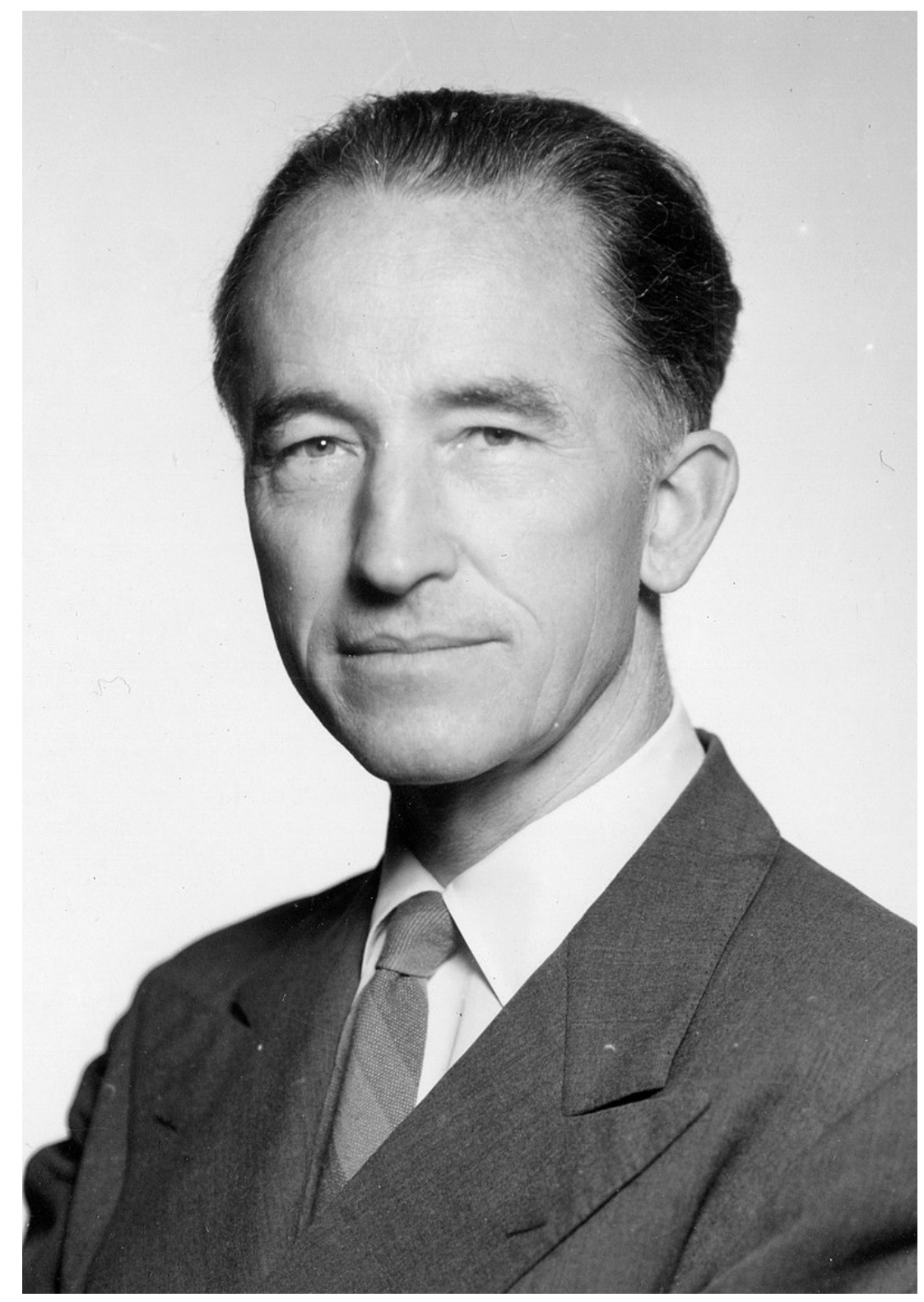

\section{Advances in Geophysics}

volume 10, 1964, Pages 1-82

\section{Atlantic Air-Sea Interaction}

J. Bjerknes

\section{田 Show more}

https://doi.org/10.1016/S0065-2687(08)60005-9

\section{Publisher Summary}

This article is concerned with the causes of the variations in the surface temperature of the Atlantic Ocean from year to year and over longer periods. The processes, which influence the ocean temperature, are partly radiative transfers, partly heat exchange at the interface of ocean and atmosphere, and partly advective heat transfers by the ocean currents. The net radiative heat balance of the ocean is influenced by possible variations of the solar radiative output, and by the transmissivity of the atmosphere for short- and long-wave radiation.

Variations in cloudiness would be the factor, most likely to influence measurably the annual radiative heat budget of the ocean. The ocean currents provide important contributions to the local heat budget, positive in the warm currents and negative in the cold currents. The changes in intensity of the oceanic circulation are mainly dictated by changes in the atmospheric circulation, and the resulting changes in the temperature field of the ocean surface must in turn, influence the thermodynamics of the atmospheric circulation. A clarification of these relationships is a prerequisite for the understanding of the mechanism of climatic change. This article will present some empirical findings, which have a hearing on those nroblems. Before nroceeding to disnlav the emnirical findings on 


\section{Motivation}

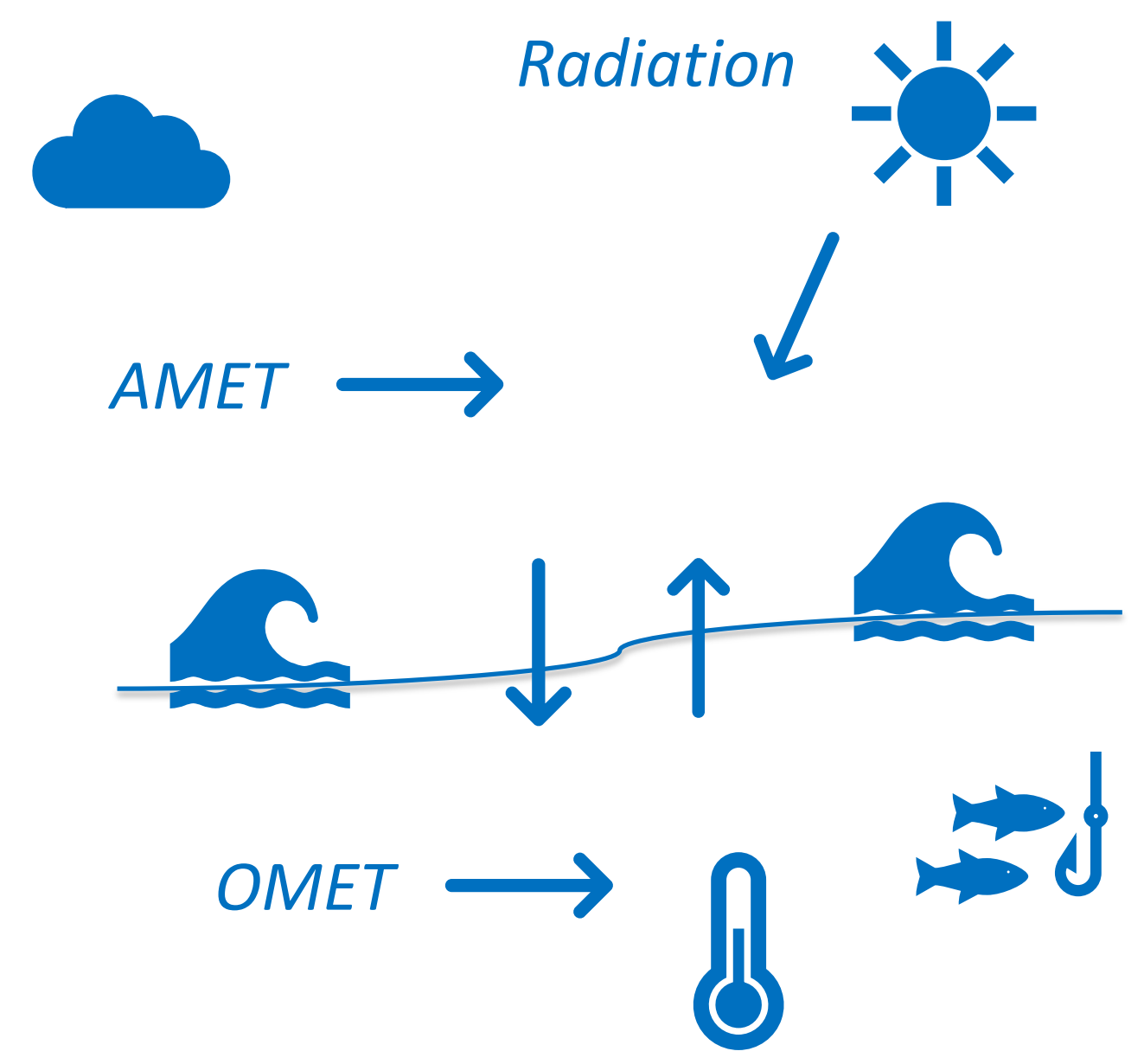

$\mathrm{OHC}$ $\frac{\partial O H C}{\partial t} \approx-\nabla(O M E T+A M E T)+F_{T O A}$

At long time scales close to equilibrium (MET=Meridional Energy Transport)

$$
O M E T \approx-A M E T
$$

1) Evidence in numerical climate models. Does it occur in the observationally constrained reanalysis products?

2) If so, what processes are involved to achieve compensation? 


\section{Data}

\begin{tabular}{|c|c|c|c|c|}
\hline - & ERA-Interim & $1979-2016$ & 6 hourly & $0.75^{\circ} \times 0.75^{\circ} \times 60 \mathrm{lev}$ \\
\hline - & MERRA2 & $1980-2016$ & 3 hourly & $0.5^{\circ} \times 0.667^{\circ} \times 70 \mathrm{lev}$ \\
\hline - & JRA55 & $1979-2015$ & 6 hourly & $0.56^{\circ} \times 0.56^{\circ} \times 60 \mathrm{lev}$ \\
\hline - & ORAS4 & $1979-2014$ & monthly & ORCA1 \\
\hline - & GLORYS2V3 & $1993-2014$ & monthly & ORCA025 \\
\hline - & SODA3 & $1980-2015$ & 5 daily & MOM5 \\
\hline
\end{tabular}

Six reanalysis products are used to compute the AMET and OMET 


\section{Mean and variability in AMET and OMET}

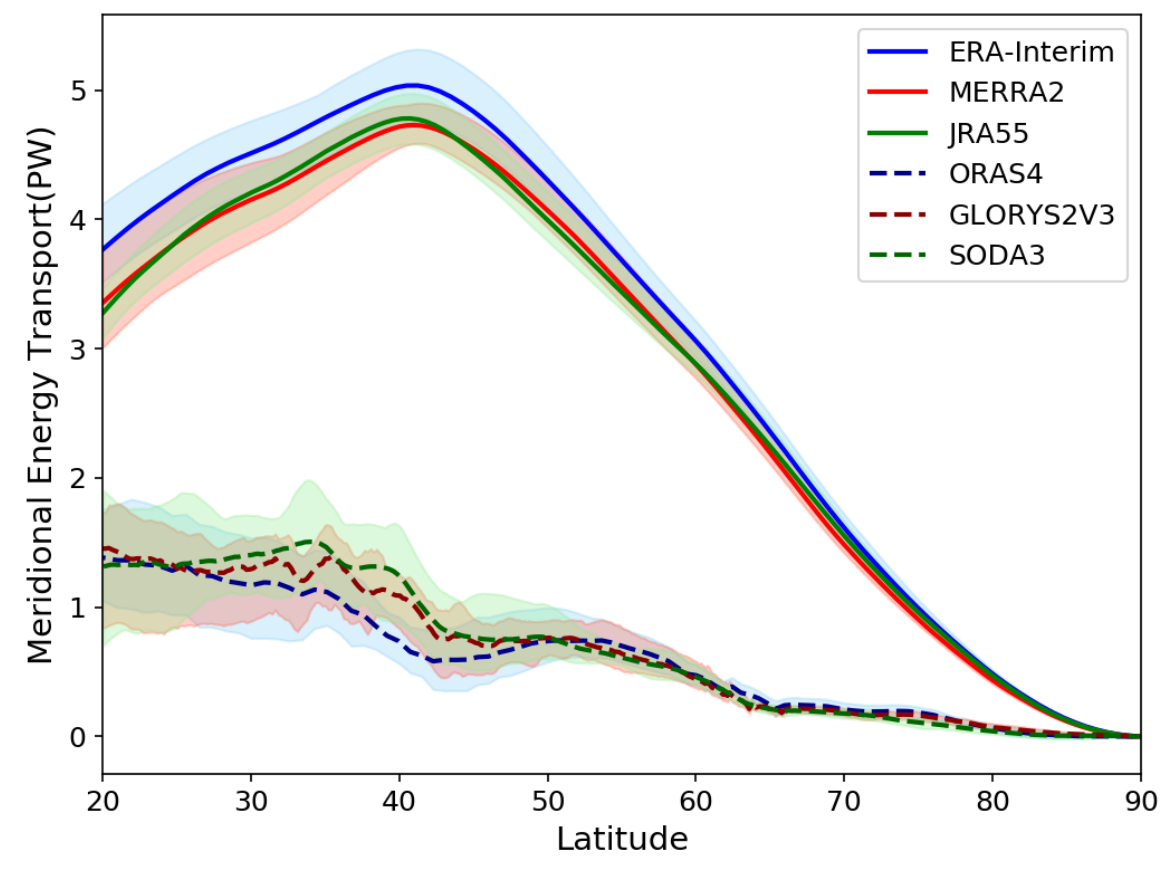

(a)

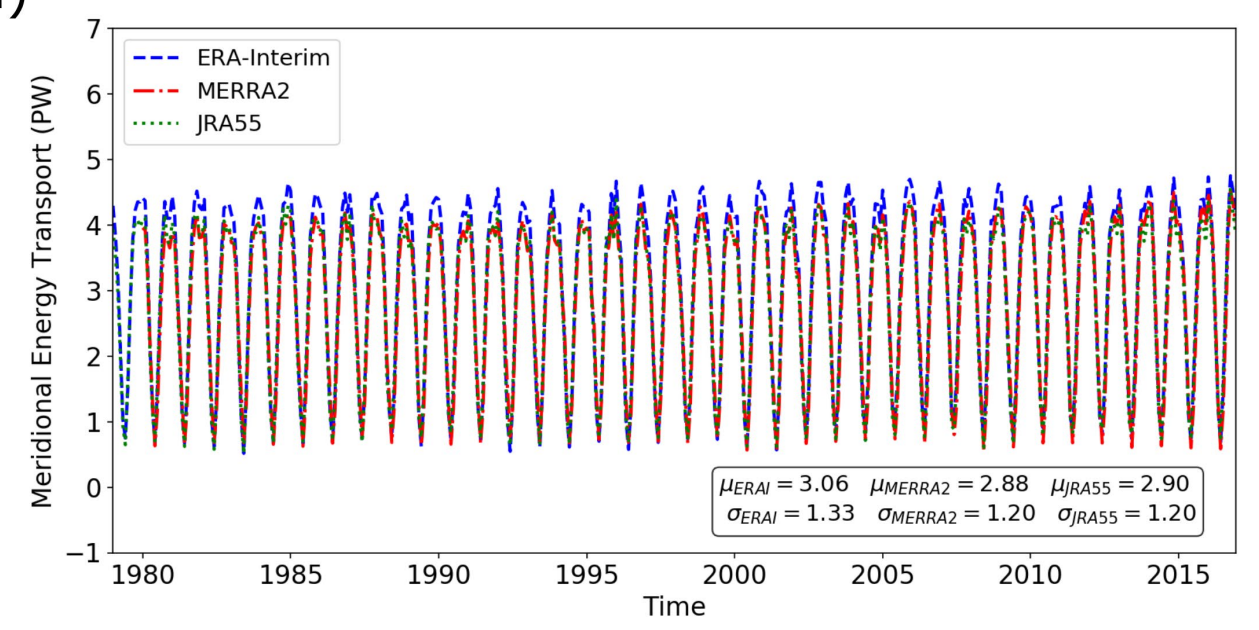

(b)

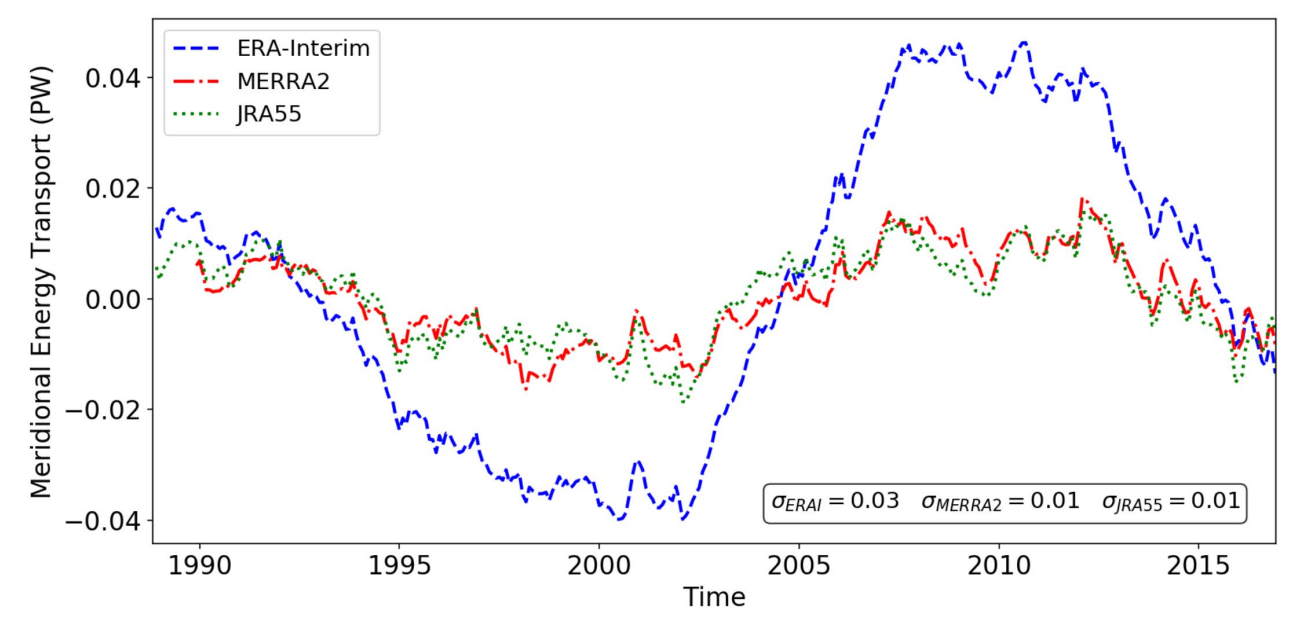

Time series of the zonal integral of AMET at $60 N$. (a) The original time series (i.e., no filter) and (b) the anomalies with a low pass filter after detrending. 


\section{Heat transport compensation between the atmosphere and}

Lag regression of OMET anomalies on AMET in the Northern Hemisphere.

Similar results are found in the reanalysis products and numerical models, but at different time scales and not in subtropics.

ERAInterim and ORAS4 (decadal)

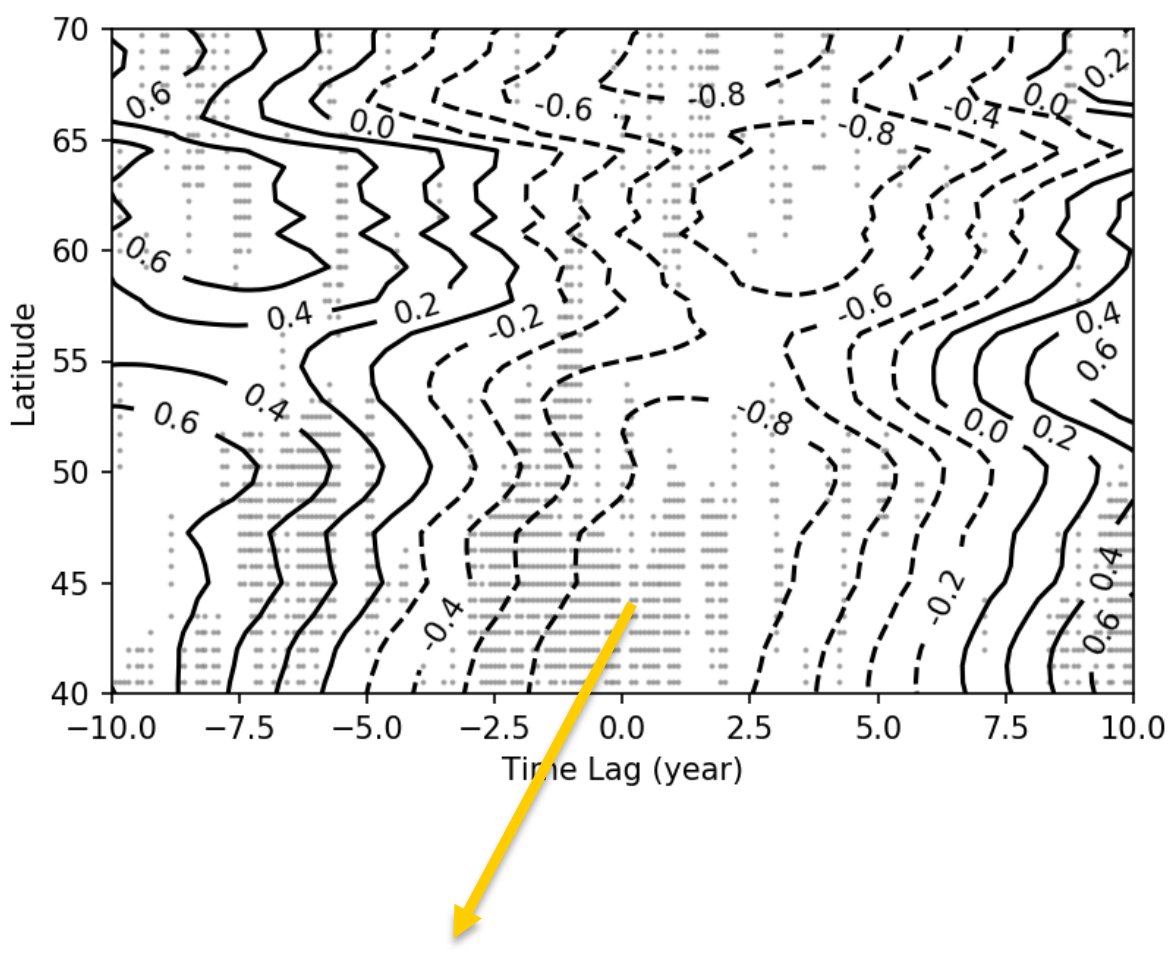

Compensation at lag 0
HadCM3 (interdf,cadal)

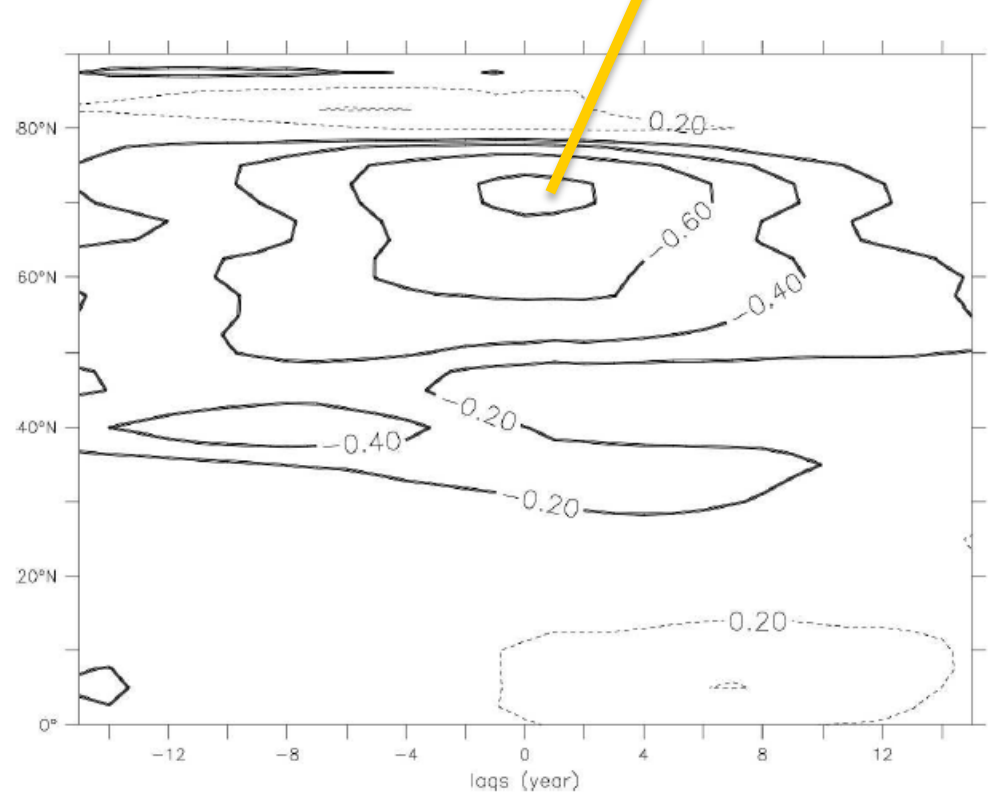

van der Swaluw, E., Drijfhout, S. S., \& Hazeleger, W., 2007; (note contouring convection different) 


\section{Heat compensation between the atmosphere and ocean}

(a)

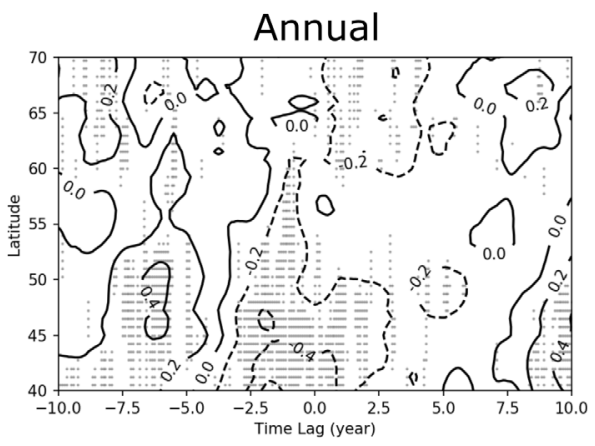

(d)

MERRA2

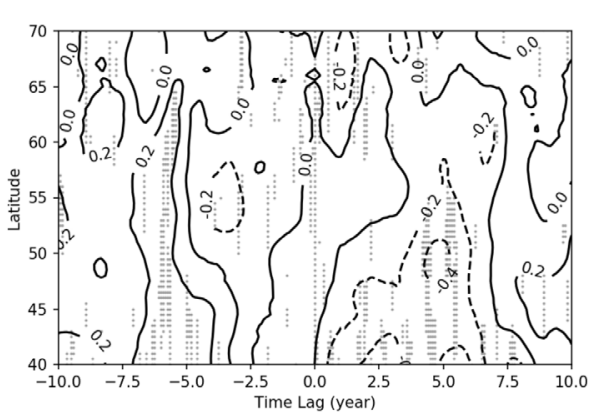

(g)

JRA55 (b)

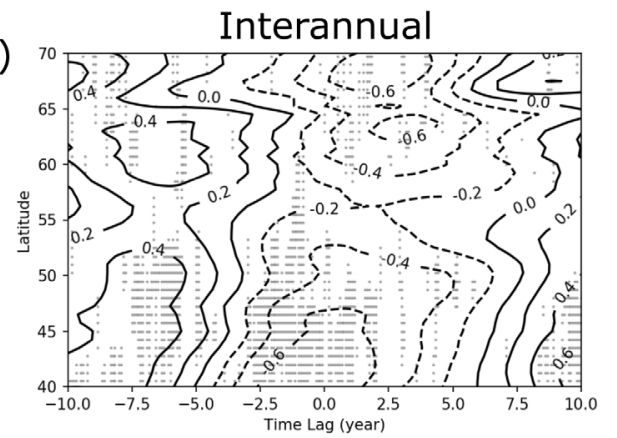

(e)

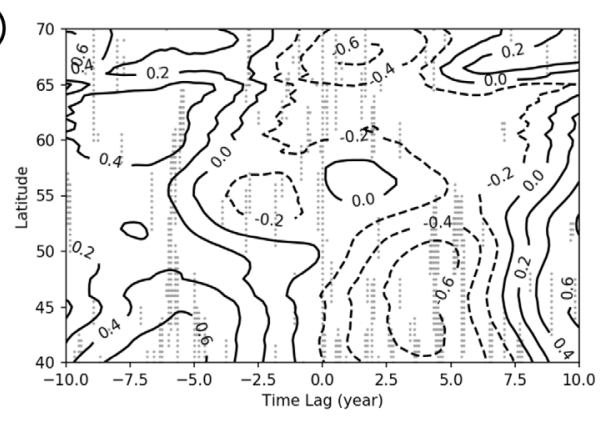

(h)

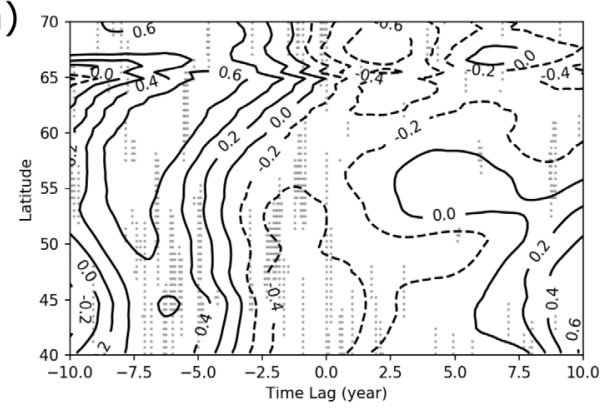

(c)

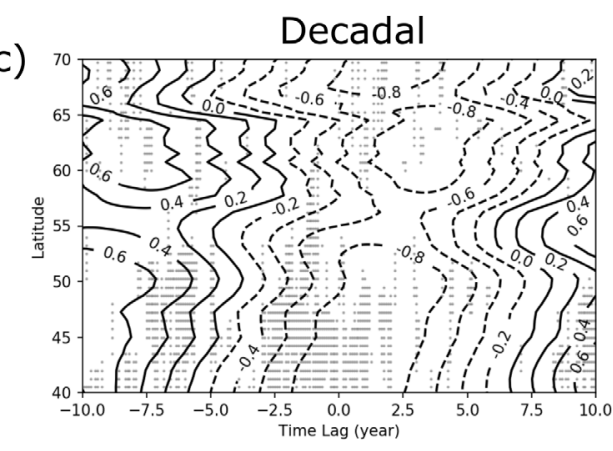

(f)

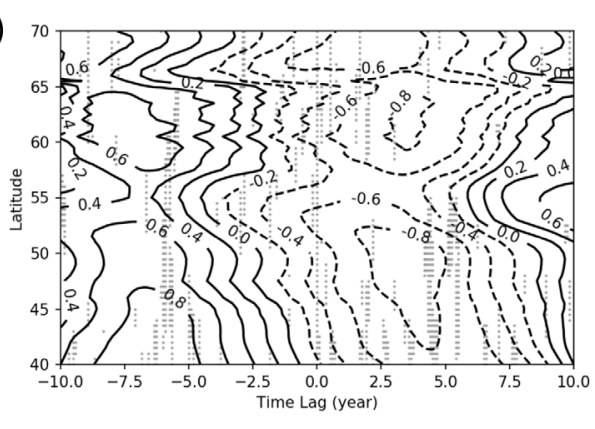

(i)

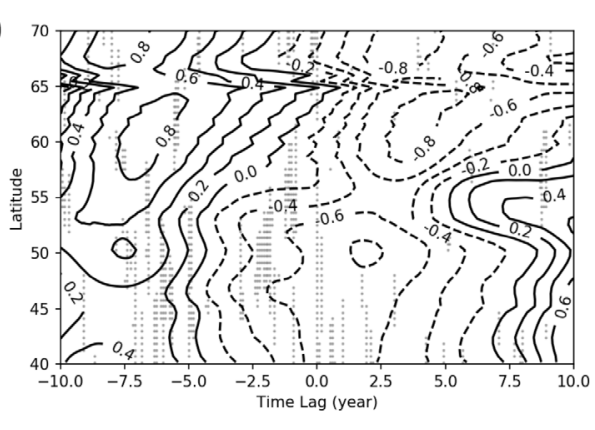

Lag regression of OMET anomalies on AMET anomalies in the Northern Hemisphere at (left) annual, (center) interannual, and (right) decadal time scales.

Positive time lag indicates that ocean leads the atmosphere and vice versa. 


\section{Surface heat flux}

(b) MERRA2

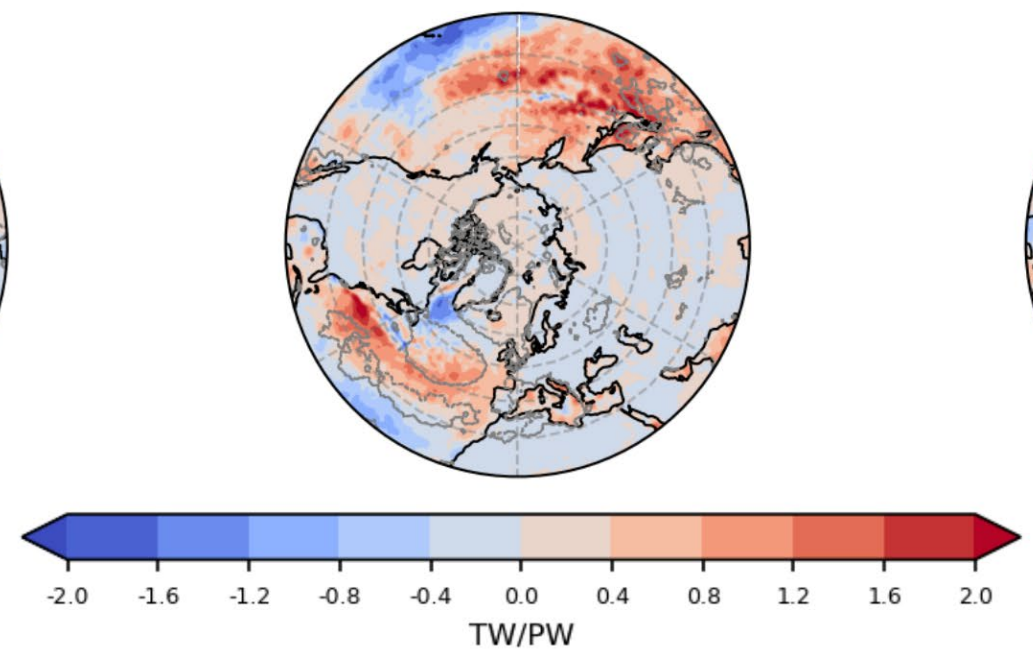

(c) (a) ERA-Interim

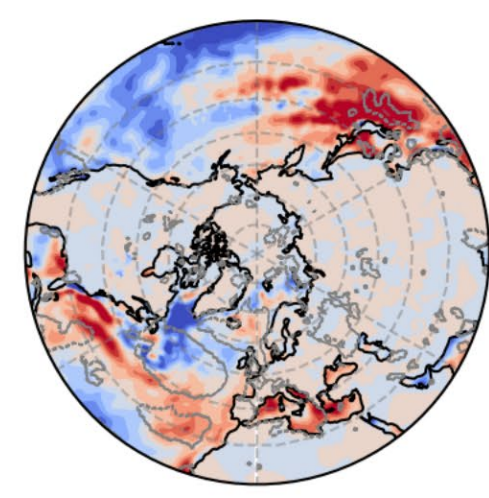
JRA55

Regression of net surface flux anomalies on vertically integrated OMET anomalies at $60 \mathrm{~N}$ at decadal time scales.
Heat is released from atmosphere to the ocean at subtropical regions and is passed from ocean to the atmosphere at subpolar regions over the Atlantic. 


\section{Atmospheric response} to OMET variations

Regressions are shown in colors. Mean meridional stream function in contours.

High level atmospheric heat transport accounts for compensation of ocean heat transport $\rightarrow$ dynamical processes at play
Regression of AMET on

OMET at $60 \mathrm{~N}$

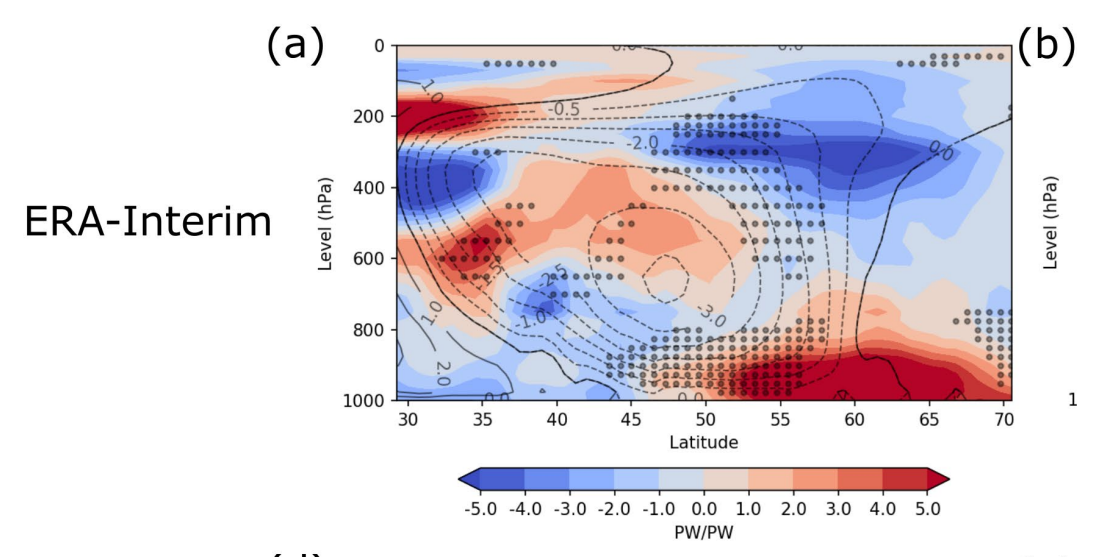

MERRA2

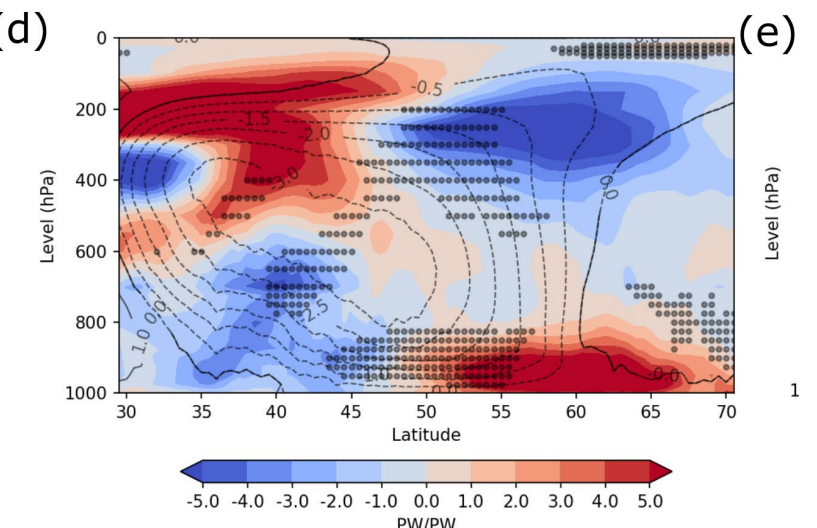

JRA55

(g)

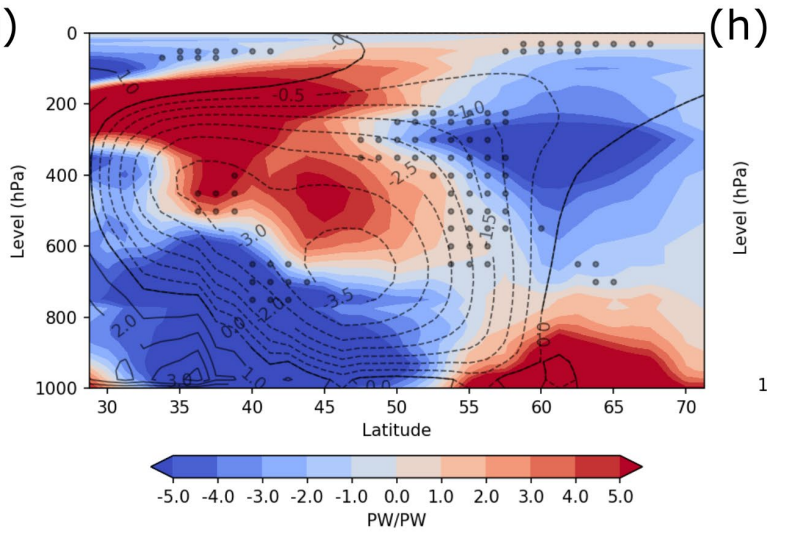




\section{Atmospheric response}

to OMET variations

Regression of stream

function on OMET at $60 \mathrm{~N}$

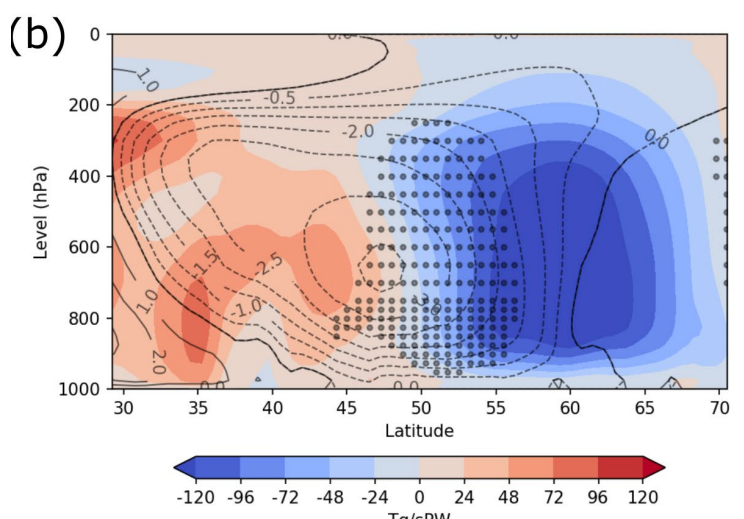

Indeed, Ferrell cell responds.
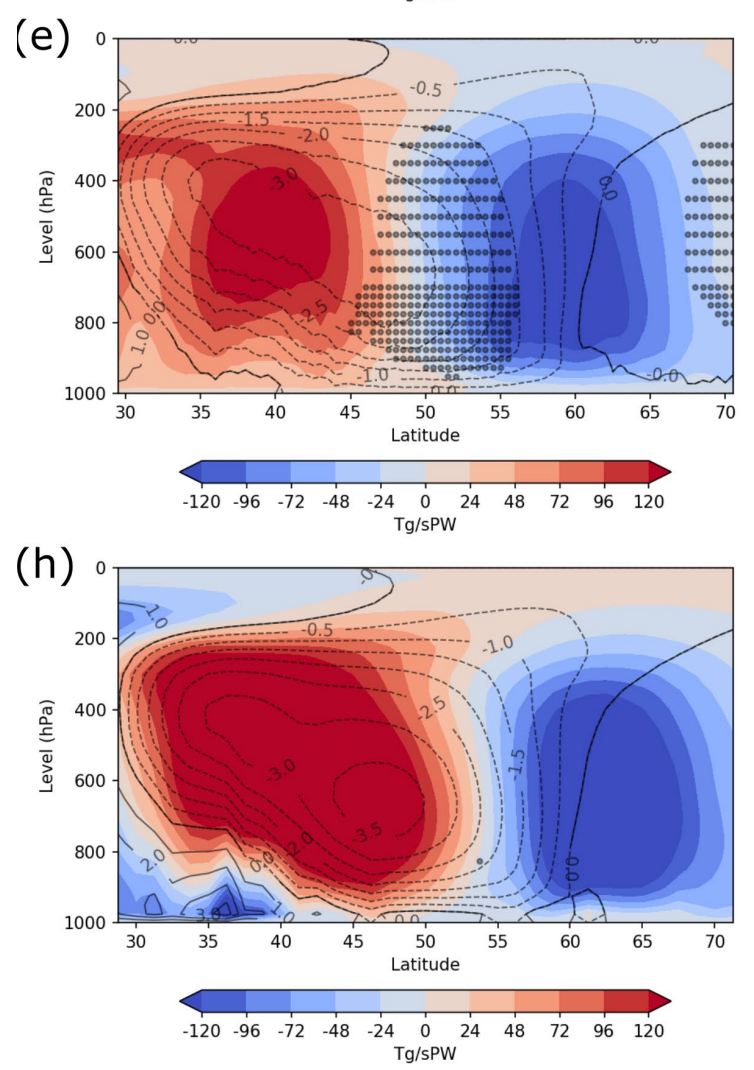


\section{Atmospheric response} to OMET variations

Consistent changes of baroclinicity of the atmosphere

Consistent result across data sets
Regression of $d u / d z$ on

OMET at $60 \mathrm{~N}$
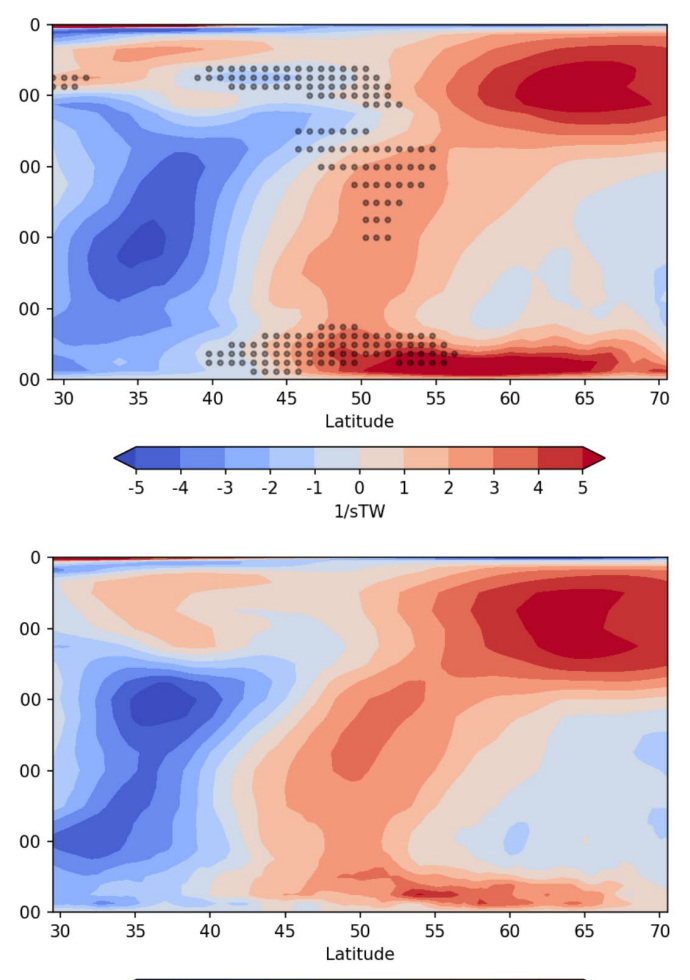

\begin{tabular}{llllllllllllll}
\hline-5 & -4 & -3 & -2 & -1 & 0 & 1 & 1 & 3 & 4 & 5
\end{tabular}

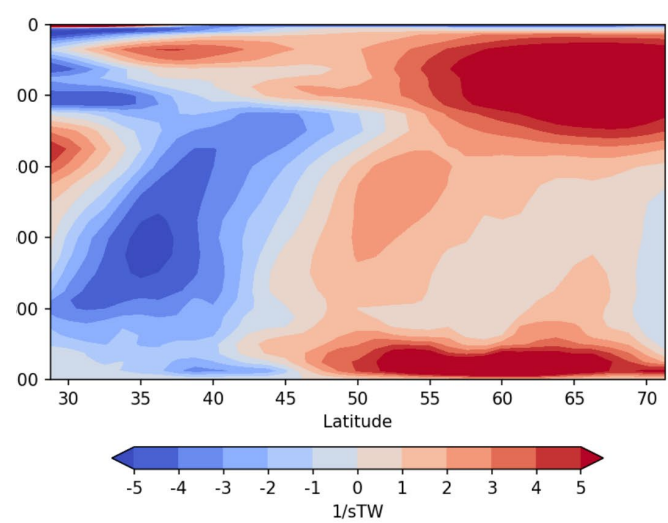




\section{Atmospheric response to OMET variations}

Changes of baroclinicity of the atmosphere

Results between reanalysis and

Regression of du/dz (ERAInterim) on OMET (ORAS4) at 60N

$$
100
$$

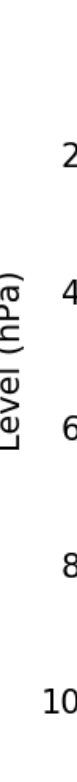

numerical climate models are different!
Regression of du/dp on OMET (HadCM3) at $70 \mathrm{~N}$

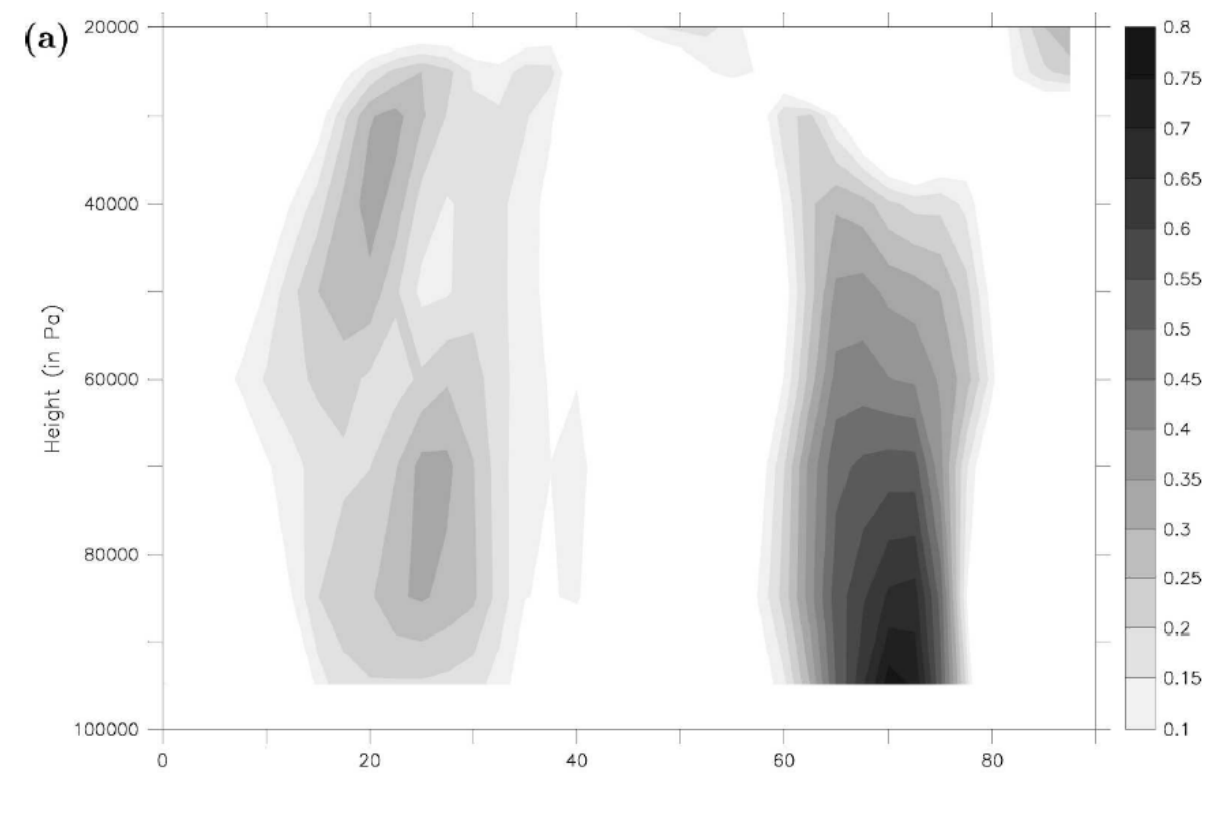

van der Swaluw, E., Drijfhout, S. S., \& Hazeleger, W., 2007; 


\section{Eddy momentum}
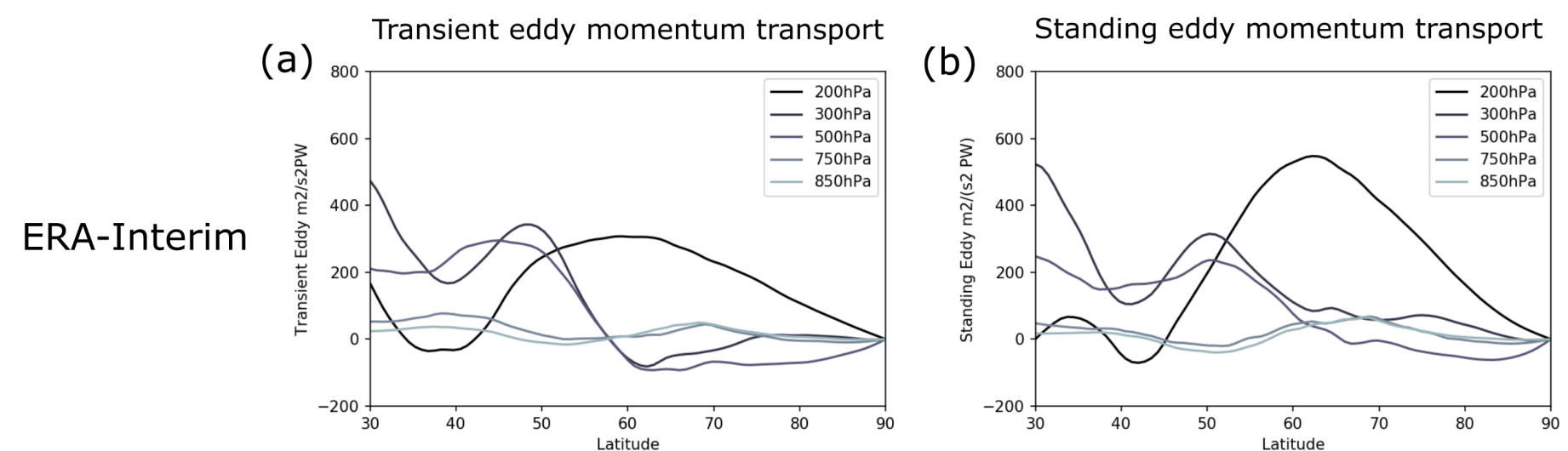

transport

MERRA2
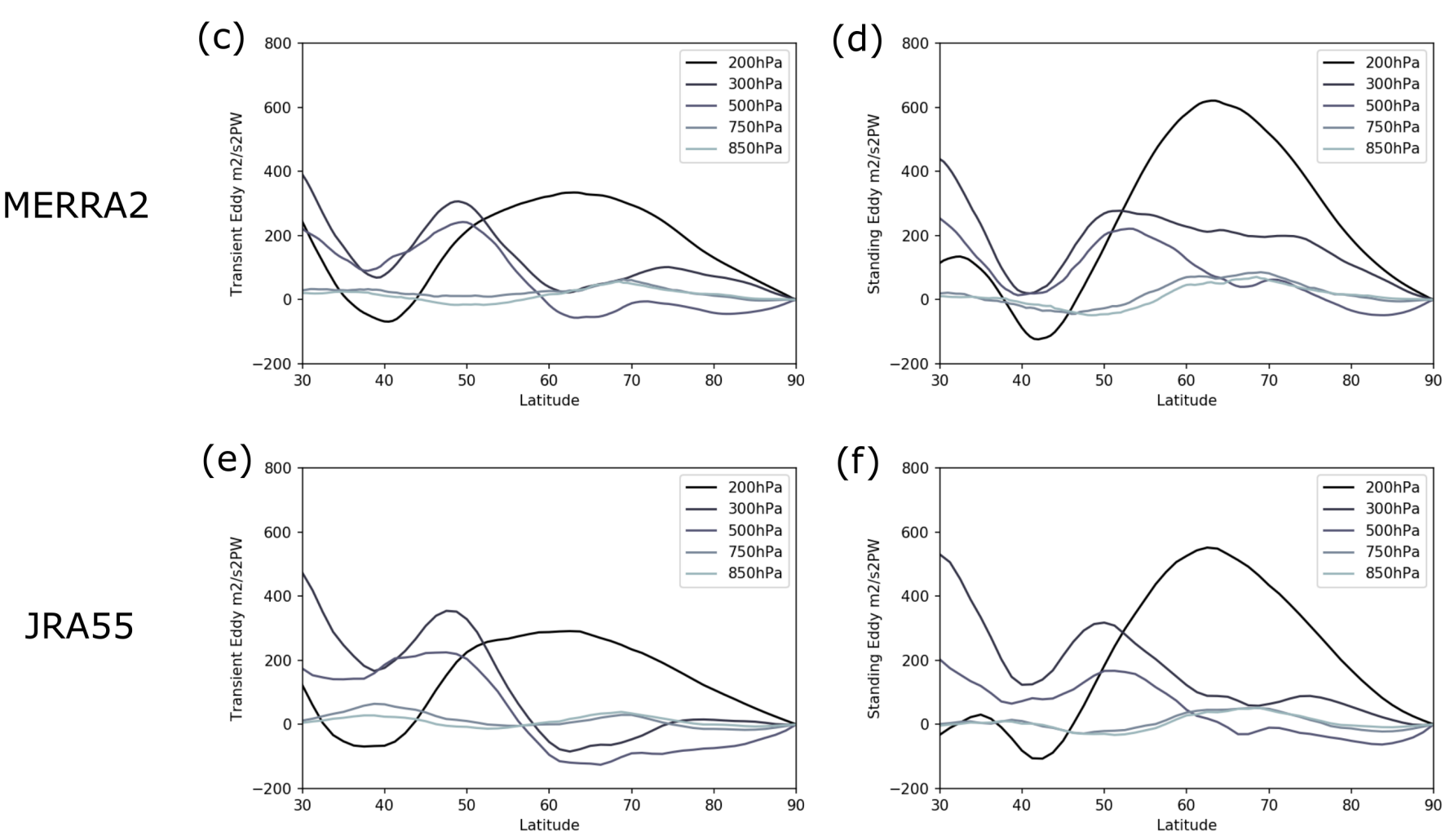

- Momentum transported by standing / transient eddies

- Mean flow variations are quite likely to be driven by eddies 


\section{Atmospheric response to OMET variations}

Regression of geopotential height anomalies at $500 \mathrm{hPa}$ on vertically integrated OMET anomalies at $60 \mathrm{~N}$

(a) ERA-Interim

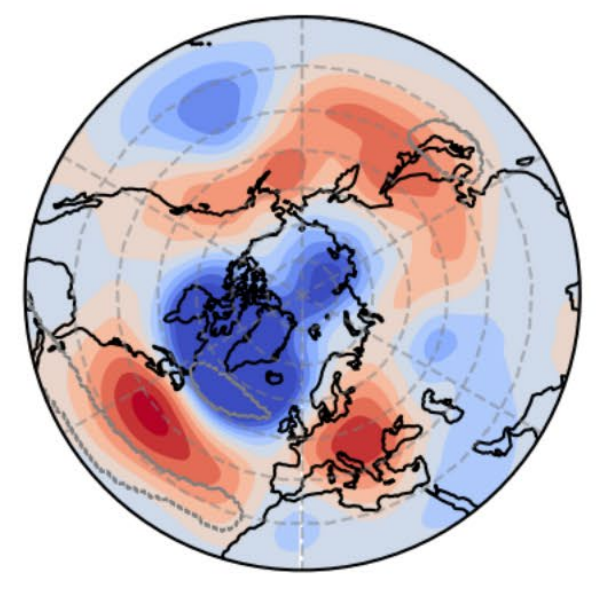

(b)

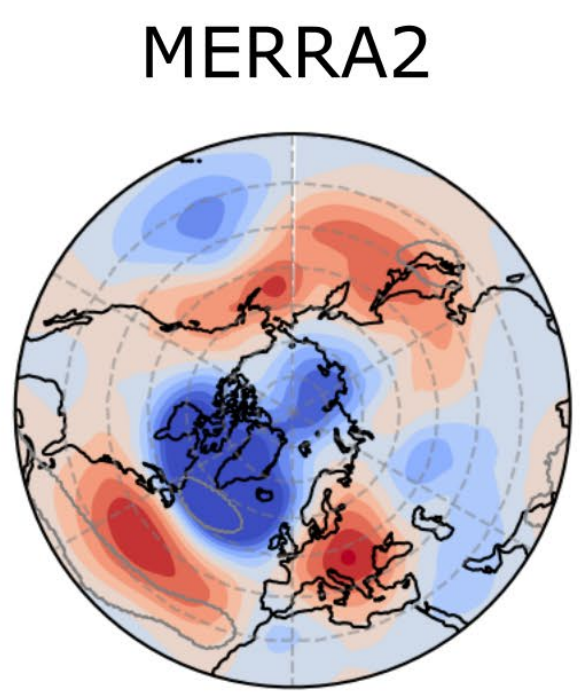

(c)

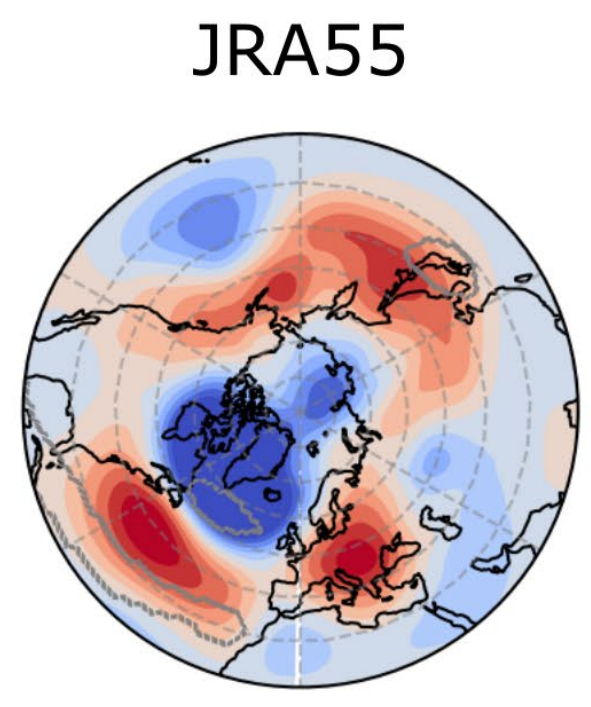

Horizontally the shift in the Ferrel Cell shows as an AO/NAO pattern. 


\section{Conclusion}

1. We find Bjerknes compensation in reanalysis data. This is similar to studies with numerical climate models, but different time scales and also in subtropics.

2. The atmosphere responds to OMET variations with a shift in the Ferrel Cell. This shift may be driven by eddy momentum fluxes due to change in baroclinicity. Horizontally this shift shows an AO like response.

3. The related AMET variations are primarily found in the zonal mean part, driven by eddy momentum fluxes, and less in the eddy heat transport part. This is significantly different from models, but it is consistent among reanalysis products.

4. The oceanic response to AMET variations is primarily wind-driven (Ekman and Sverdrup), but we cannot discard AMOC variations due to thermohaline processes (not shown). 
The information in this presentation has been compiled with the utmost care, but no rights can be derived from its contents. 


\section{Backup slides}


(a) ERA-Interim

(b)

MERRA2

(c)

JRA55
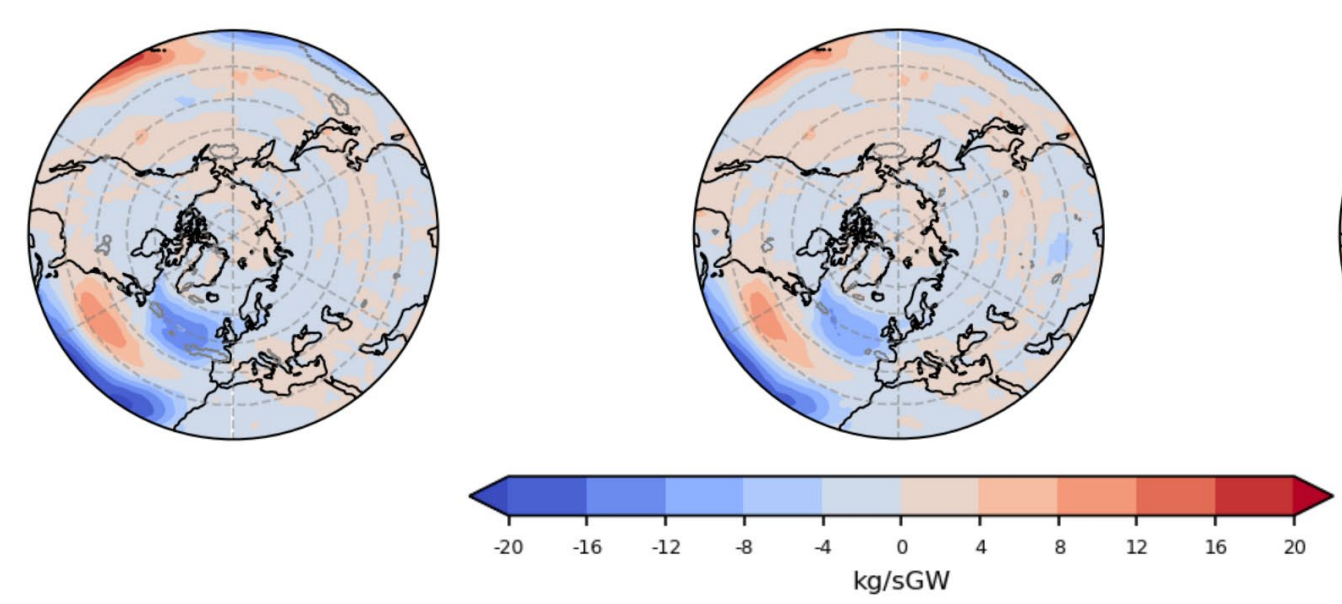

Oceanic response to AMET variations

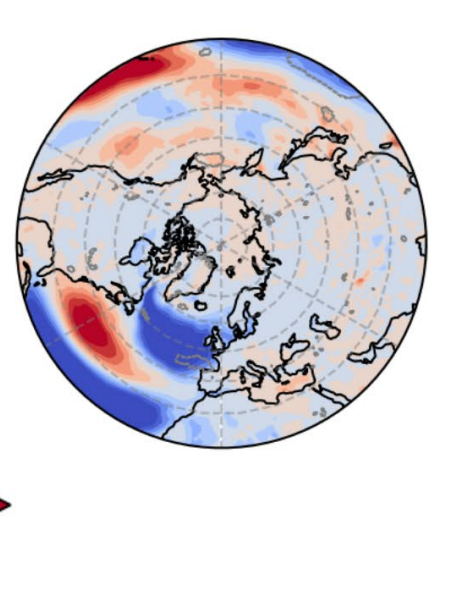

Regression of meridional

Ekman transport anomalies

on vertically integrated OMET

anomalies at $60 \mathrm{~N}$

(a) ERA-Interim

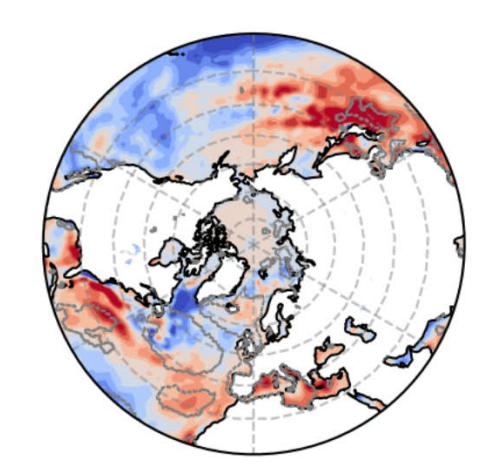

Regression of buoyancy forcing anomalies on vertically integrated OMET anomalies at $60 \mathrm{~N}$ at decadal time scales without time lags. (b) MERRA2

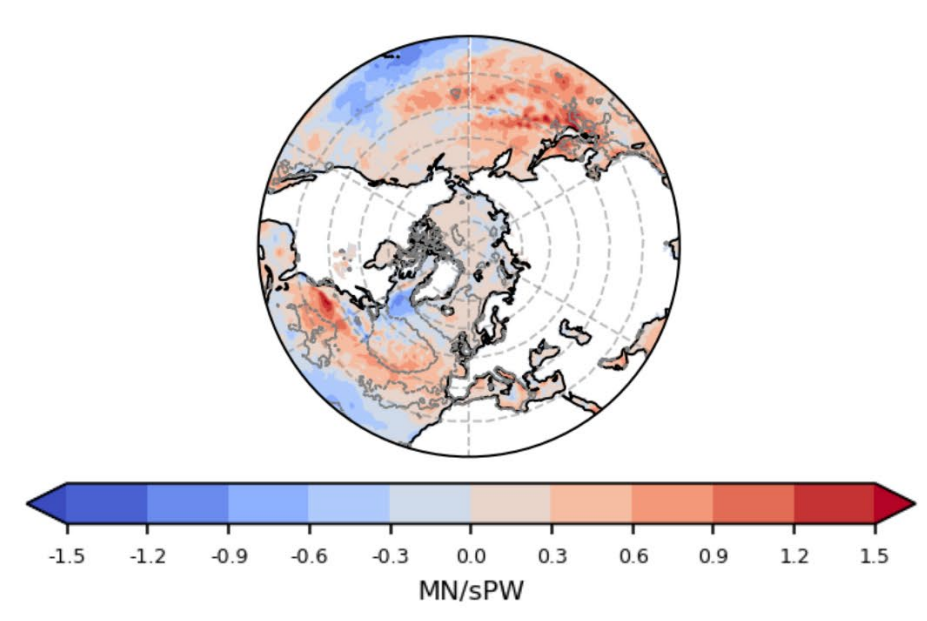

(c)

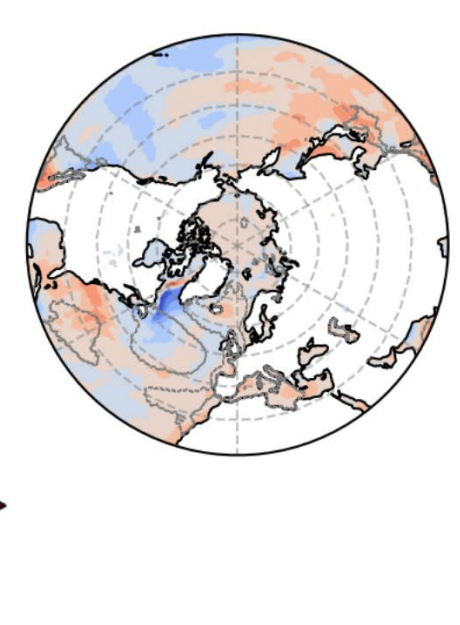

- Surface wind driven (Ekman/Sverdrup transport)

- Buoyancy forcing driven

(Thermal/Saline force) 


\section{Computation of AMET and OMET}

Compute AMET and OMET and their anomalies as a function of latitude in the Northern Hemisphere.

(a)

(b)
Time series of the zonal integral of AMET at $60 \mathrm{~N}$. (a) The original time series (i.e., no filter) and (b) the anomalies with a low pass filter after detrending.
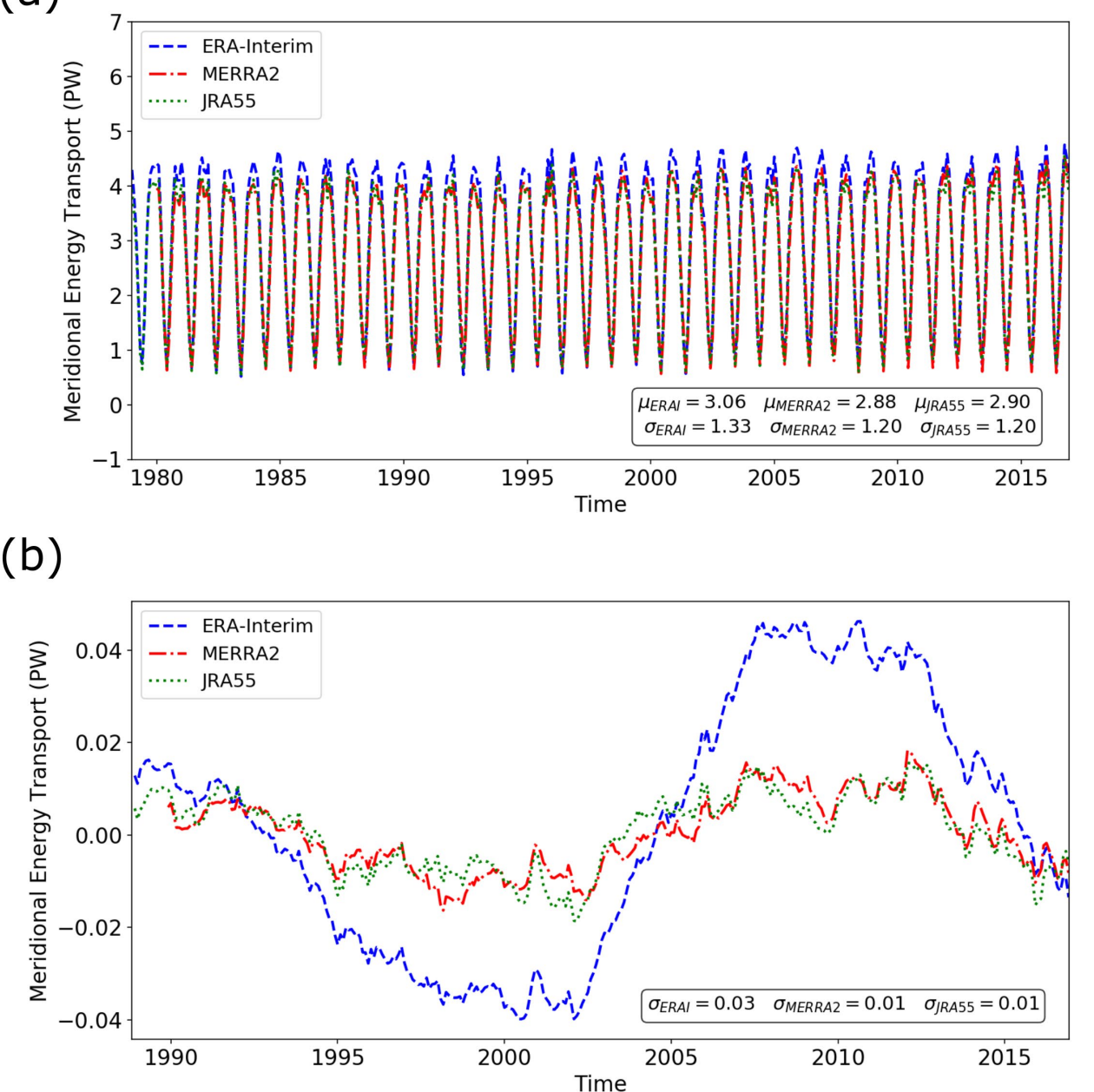

Time series of the zonal integral of OMET at $60 \mathrm{~N}$. (a) The original time series (i.e., no filter) and (b) the anomalies with a low pass filter after detrending.

(a)

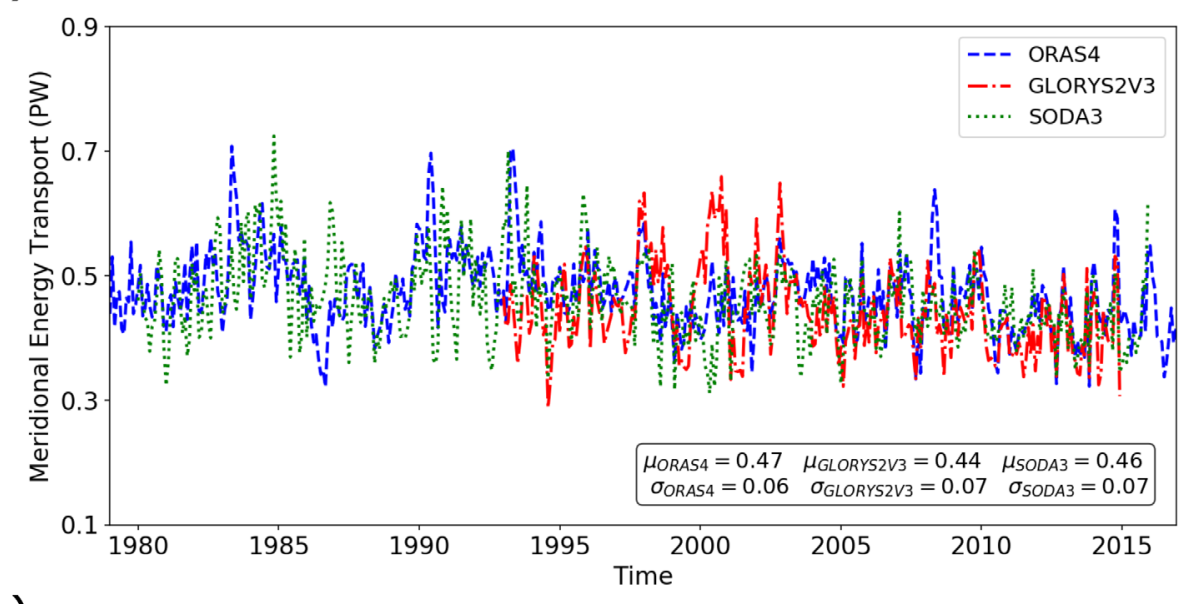

(b)

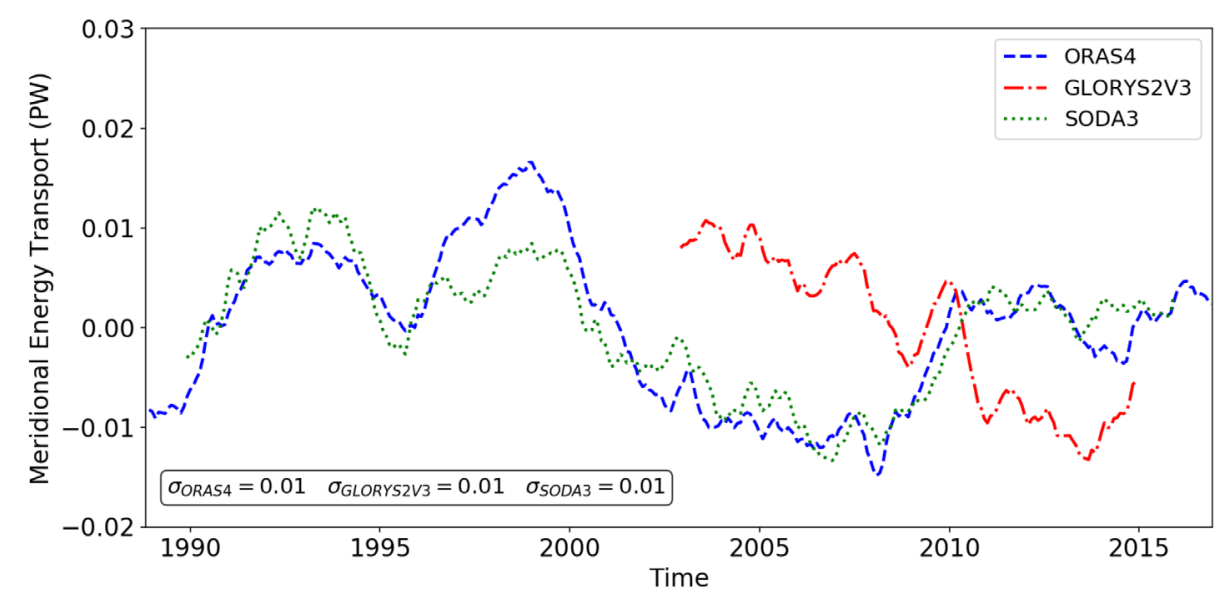




\section{Eddy Energy Transport}
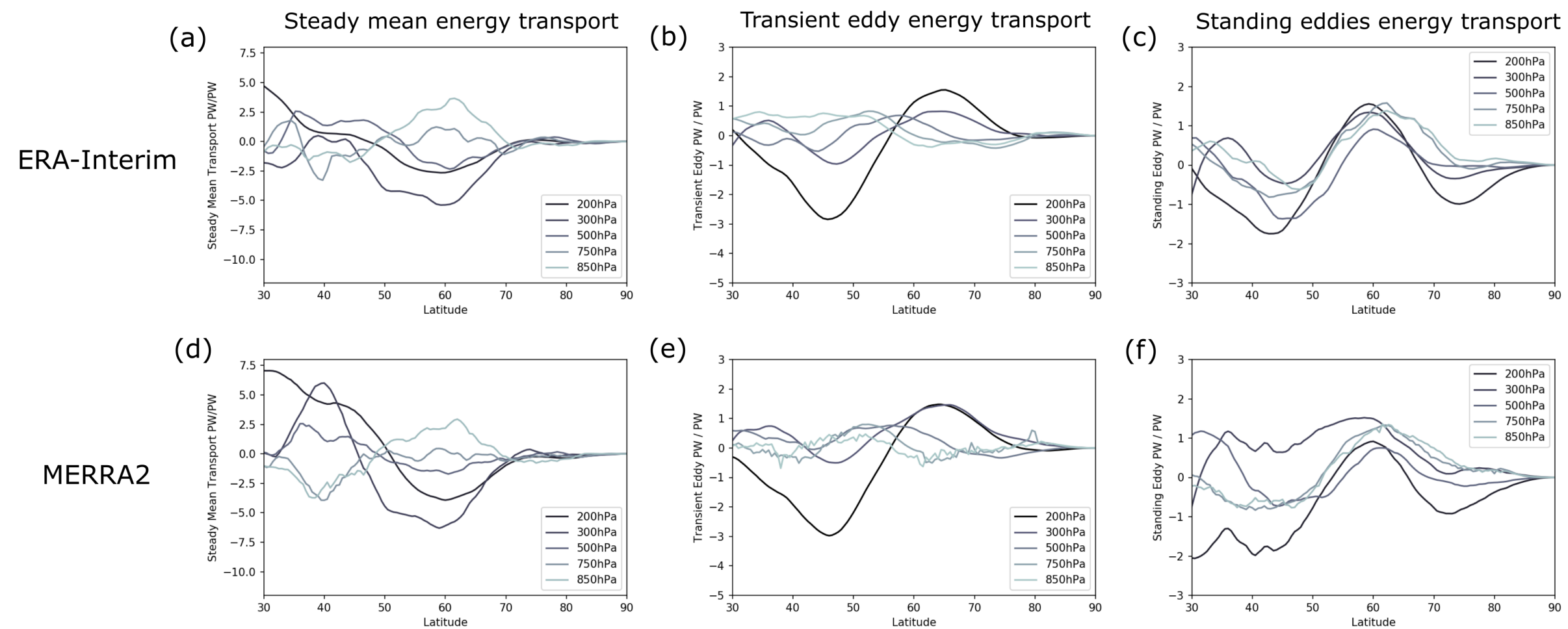

(e)
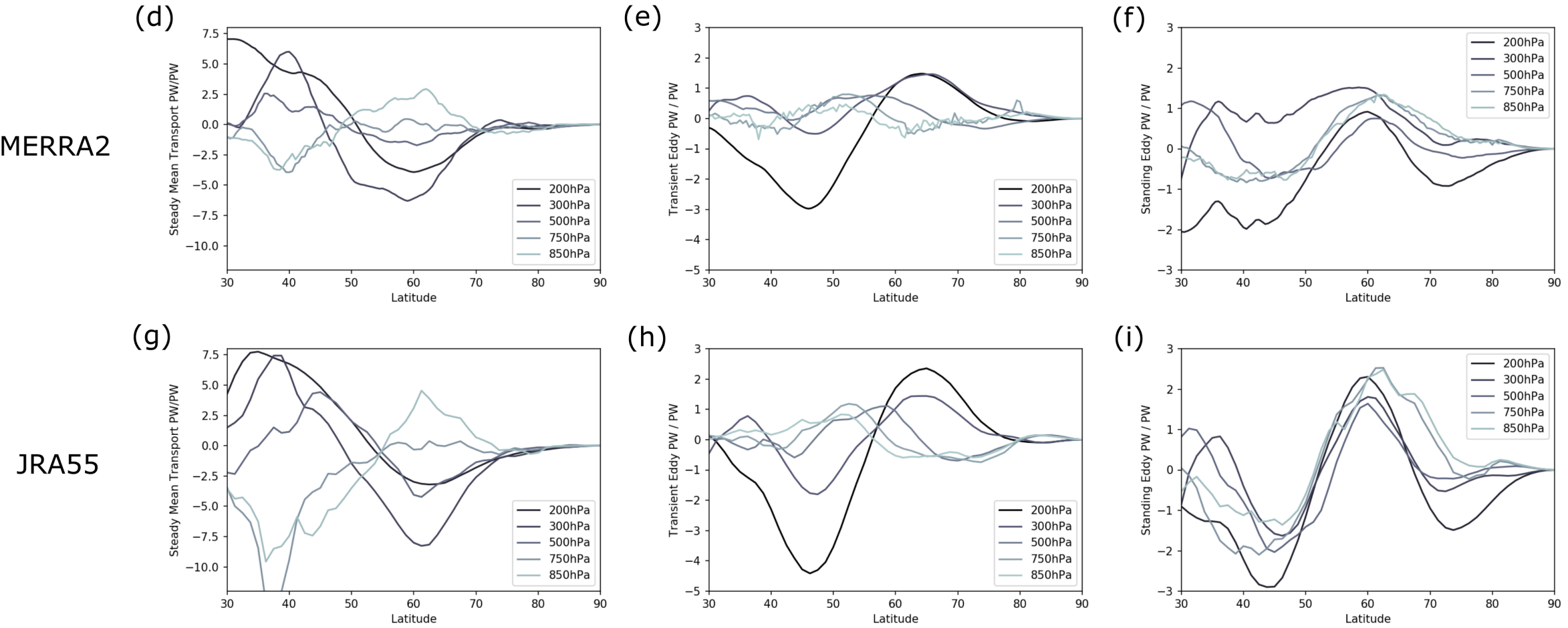

(h)

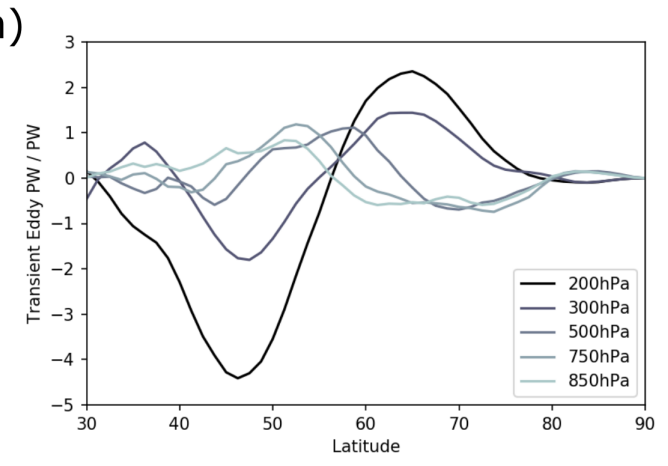

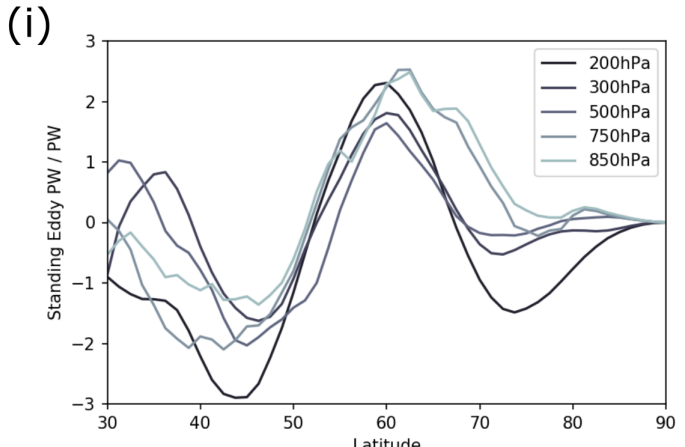




\section{Impact of wind stress curl}

on gyres

Regression of SSH anomalies on vertically integrated OMET anomalies at $60 \mathrm{~N}$ at decadal time scales.

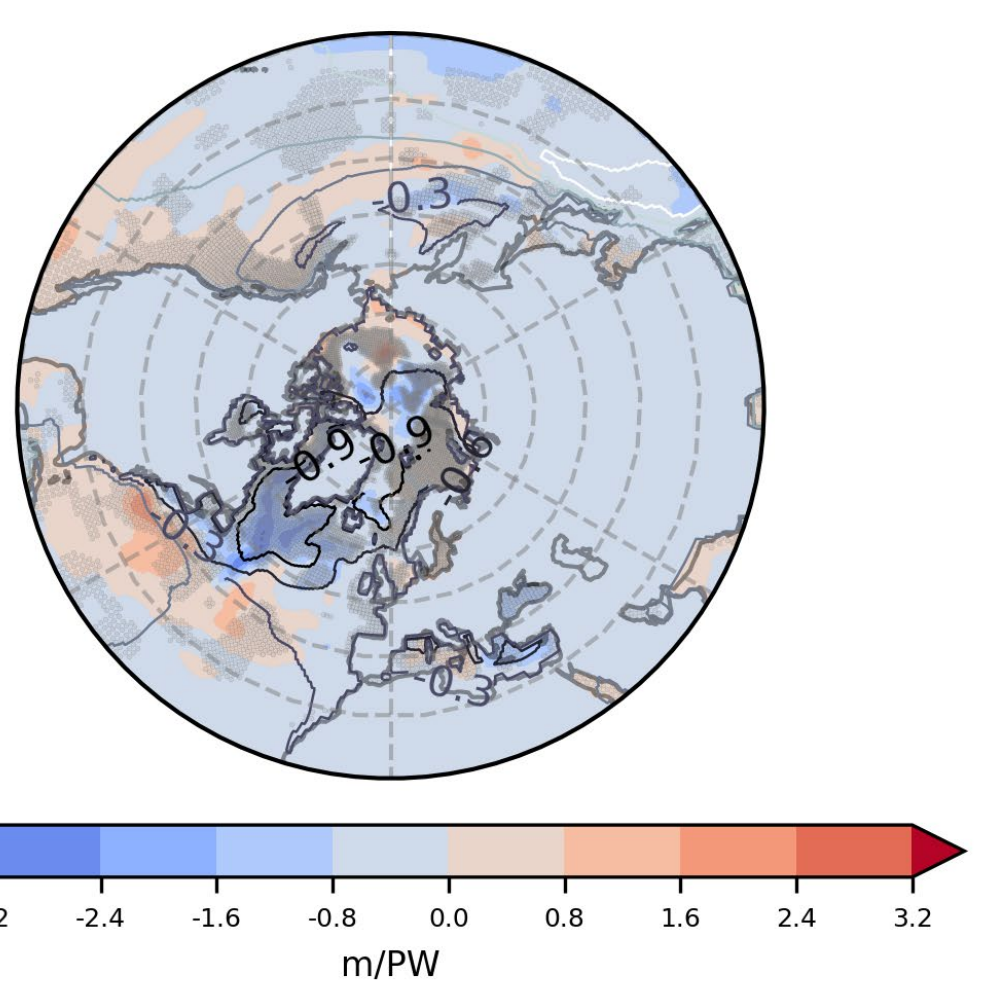

